\title{
EGLN2 and RNFI 50 genetic variants are associated with chronic obstructive pulmonary disease risk in the Chinese population
}

This article was published in the following Dove Press journal:

International Journal of COPD

13 January 2015

Number of times this article has been viewed

\author{
Yipeng Dingl,* \\ Huan Niu',* \\ Hua Yang ${ }^{2}$ \\ Pei Sun' \\ Yu Chen ${ }^{3}$ \\ Mengling Duan' \\ Dongchuan $\mathrm{Xu}{ }^{\prime}$ \\ Junxue $X u^{3}$ \\ Tianbo Jin ${ }^{2,4}$ \\ 'Department of Emergency, People's \\ Hospital of Hainan Province, Haikou, \\ Hainan, People's Republic of China; \\ ${ }^{2}$ School of Life Sciences, Northwest \\ University, Xi'an, People's Republic \\ of China; ${ }^{3}$ Department of Respiration \\ Emergency, The Third People's \\ Hospital of Haikou, Haikou, Hainan, \\ People's Republic of China; ${ }^{4}$ National \\ Engineering Research Center for \\ Miniaturized Detection Systems, Xi'an, \\ People's Republic of China \\ *These authors contributed equally \\ to this work
}

Correspondence: Tianbo Jin Mailbox 386, \#229 North Taibai Road, School of Life Sciences, Northwest University, National Engineering Research Center for Miniaturized Detection Systems, Xi'an 710069, Shaanxi,

People's Republic of China

Tel/fax +862988303800

Email tianbojin1973@gmail.com

Yipeng Ding

Mailbox \#19, Xiuhua Road, School of

Life Sciences, Northwest University,

National Engineering Research

Center for Miniaturized Detection

Systems, Haikou 570102, Hainan,

People's Republic of China

Tel/fax +860898 66222502

Email dingyipenghainan@163.com
Purpose: Chronic obstructive pulmonary disease (COPD) is a major and an increasingly prevalent health problem worldwide. It has been reported that genetic variation may play a role in the development and severity of COPD. The purpose of this study was to investigate whether single nucleotide polymorphisms in multiple genetic variants were associated with COPD in a Chinese population from Hainan province.

Methods: In this case-control study, including 200 COPD patients and 401 controls, we genotyped 14 tag single nucleotide polymorphisms and evaluated their association with COPD using the $\chi^{2}$ test and genetic model analysis.

Results: The polymorphism, rs 10007052, in the RNF150 gene was significantly associated with COPD risk at a $5 \%$ level (odds ratio $=1.43,95 \%$ confidence interval, $1.06-1.95, P=0.020$ ). In the log-additive model, the minor allele $(\mathrm{C})$ of rs 10007052 in the $R N F 150$ gene $(P=0.026)$ and the minor allele $(\mathrm{C})$ of $\mathrm{rs} 3733829$ in the $E G L N 2$ gene $(P=0.037)$ were associated with COPD risk after adjustment for age, sex, and smoking status. Further haplotype analysis revealed that the "CT" haplotype composed of the mutant allele (C) of rs7937, rs3733829 in the EGLN2 gene, was associated with increased COPD risk (odds ratio $=1.55 ; 95 \%$ confidence interval, 1.05-2.31; $P=0.029)$.

Conclusion: Our findings indicated that rs10007052 in the RNF150 and rs3733829 in the EGLN2 gene were significantly associated with the risk of COPD in Chinese populations of Hainan province. These data may provide novel insights into the pathogenesis of COPD, although further studies with larger numbers of participants worldwide are needed for validation of our conclusions.

Keywords: case-control studies, COPD, tag single-nucleotide polymorphism

\section{Introduction}

Chronic obstructive pulmonary disease (COPD) is characterized by airflow obstruction caused by chronic bronchitis, emphysema, and/or disease of small airways. ${ }^{1}$ It is predicted that COPD will be the third leading cause of death worldwide by 2020 , and will, thus, impose an even greater burden on health care systems globally. ${ }^{2}$ In the People's Republic of China, many people suffer from this disease and a large number die prematurely because of its complications. Therefore, there is an urgent need to prevent and treat this devastating lung disease through better understanding of its pathogenesis. The most important exogenous risk factor for developing COPD is inhalation of tobacco smoke. However, the fact that fewer than $20 \%$ of smokers develop $\mathrm{COPD}^{3-5}$ suggests that other factors besides smoking, such as genetic variation, may play a role in the development and severity of COPD..$^{6-8}$ 
Many studies of candidate genes for COPD and pulmonary function have been conducted over the past few years. Of these, genome-wide association (GWA) studies have identified some loci associated with susceptibility to COPD, ${ }^{9-11}$ but with varying degrees of reproducibility. Conflicting results among these studies may be attributable to differences in ethnicity and sample sizes. Furthermore, few studies performed on the Chinese population have focused on COPD. The previous gene studies of the Chinese population have only focused on the Han population, but Hainan is a multiethnic mix province, while Han and $\mathrm{Li}$ are the two main ethnicities, and the incidence of COPD in the Hainan population is higher than that of other regions of China. Therefore, to explore the contribution of genetic factors to the development of COPD in the Chinese population, we performed a case-control study of a Chinese population of Hainan province to identify loci associated with COPD among 14 single-nucleotide polymorphisms (SNPs) of eleven genes.

\section{Materials and methods Study participants}

We recruited 200 subjects (58 females, 142 males; median age, 71.70 years) who were diagnosed with COPD at People's Hospital of Hainan Province. COPD was newly diagnosed according to the criteria established by the NHLBI (National Heart, Lung, and Blood Institute)/WHO Global initiative for chronic Obstructive Lung Disease (GOLD). ${ }^{12}$ The entry criteria for COPD cases were post-bronchodilator forced expiratory volume in 1 second (FEV1) $<80 \%$ predicted and FEV1/forced vital capacity $<0.7$. The controls were selected based on post-bronchodilator FEV1 $>80 \%$ predicted and FEV1/forced vital capacity $>0.7$. The severity of COPD was classified by the guidelines of GOLD in terms of the percentage predicted FEV1: mild (>80\%), moderate $(50 \%-80 \%)$, severe $(30 \%-50 \%)$, or very severe $(<30 \%)$. Patients were excluded from the study if they had other significant respiratory diseases, such as lung cancer, pulmonary tuberculosis, cystic fibrosis, or bronchial asthma.

Smoking habit was defined as follows: nonsmokers had never smoked; ex-smokers had smoked daily and given it up prior to entering the study; smokers smoked daily at the time of the study.

In addition, 401 randomly selected healthy individuals (115 females, 286 males; median age 48.58 years) were taken as a control group, which included current or ex-smoker with no known disease, no history of any disease, and no airflow limitation. All participants were from Li and Han populations of Hainan province.

\section{Demographic and clinical data}

Demographic and personal data were collected through an in-person interview using a standardized epidemiological questionnaire that included age, sex, ethnicity, residential region, diet, smoking history, and family history of COPD. All of the participants signed informed consent forms at the start of the study. Five milliliters of peripheral blood was taken from each subject according to the study protocol approved by the People's Hospital of Hainan Province.

\section{Tag SNPs selection and genotyping}

GWA studies have identified some loci associated with susceptibility to COPD. ${ }^{10,13-17}$ Of these, SNP variants, have been researched in Chinese, however, the results in GWA and Chinese studies were inconsistent across studies. We selected 14 tag SNPs (tSNPs) from eleven genes that were previously reported to be associated with COPD with minor allele frequency $>5 \%$ in the HapMap Chinese Han Beijing population. Genomic DNA was extracted from whole blood using the GoldMag-Mini Whole Blood Genomic DNA Purification Kit (GoldMag Co. Ltd., Xi'an City, People's Republic of China). DNA concentration was measured using a NanoDrop 2000 (Thermo scientific, Fitchburg, WI, USA). We used Sequenom MassARRAY Assay Design 3.0 Software (San Diego, California, USA) to design a Multiplexed SNP MassEXTEND assay. ${ }^{18}$ The SNPs were genotyped with a Sequenom MassARRAY RS1000 using the standard protocol recommended by the manufacturer. ${ }^{18}$ Data management and analysis were performed using Sequenom Typer 4.0 software. ${ }^{18,19}$ Laboratory personnel were blinded to the genotyping results of all samples.

\section{Statistical analysis}

Microsoft Excel (Microsoft Corporation, Redmond, WA, USA) and SPSS 19.0 statistical package (IBM Corporation, Armonk, NY, USA) were used to perform statistical analyses. All $P$-values in this study were two-sided and $P=0.05$ was considered the threshold for statistical significance. The genotypic distribution of each SNP in control subjects was tested for departure from Hardy-Weinberg equilibrium (HWE) using an exact test. We compared the allele frequencies of cases and controls using the Pearson's $\chi^{2}$ and Fisher's exact tests. Odds ratios (ORs) and 95\% confidence intervals (95\% CIs) were calculated by unconditional logistic regression analysis adjusted for age and sex. ${ }^{20}$ The most common genotype in the controls was used as the reference group. Associations between the selected SNPs and the risk of COPD were assessed using genotypic model analysis (codominant, dominant, recessive, over-dominant, and 
log-additive) by the website software program SNPStats. ${ }^{21}$ ORs and 95\% CIs were calculated by unconditional logistic regression analysis adjusted for age and sex. ${ }^{20}$ Akaike's information criterion and Bayesian information criterion were used to determine the best-fitting model for each SNP. We used the Haploview software package (version 4.2) and SHEsis software platform ${ }^{22}$ for analyses of linkage disequilibrium (LD), haplotype construction, and genetic association at polymorphism loci, and a $\mathrm{D}^{\prime}$ value $>0.8$ indicated that the related tSNPs formed one block. ${ }^{23,24}$

\section{Results}

The distribution of selected characteristics of the cases and controls is shown in Table 1. There were no significant differences in sex, nationality, and smoking status between the two groups ( $P=0.935,0.889$, and 0.889 , respectively); however, age was significantly different between COPD patients and healthy controls $(P<0.001)$. Variables of age, sex, nationality, and smoking status were adjusted further for any residual confounding effect in later multivariate logistic regression analyses. Because our sample size was relatively small, we did not conduct population stratification for smoking status.

Table 2 shows the minor allele frequency of all SNPs genotyped. The HWE test revealed that the genotypic distribution of rs8102683 and rs7260329 deviated from HWE in the controls of this study $(P<0.01)$. Using the $\chi^{2}$ test, one
SNP (rs10007052 in the RNF150 gene) was significantly associated with COPD risk at a 5\% level (OR $=1.43,95 \%$ CI, 1.06-1.95, $P=0.020$ ). Moreover, rs 10007052 remained significantly associated with COPD after further adjustment $(P=0.021)$. The other SNPs did not show a significant association with the risk of COPD after adjustment.

We hypothesized that harboring the minor allele of each SNP was a risk factor, compared with possessing the wild-type allele. The results of the various genetic models are displayed in Tables 3 and 4. Our analyses showed that the genotype "C/A-C/C" of rs10007052 in the RNF150 gene was associated with an increased risk of COPD in the dominant model before $(\mathrm{OR}=1.56,95 \% \mathrm{CI}, 1.08-2.24, P=0.018)$ and after (adjusted OR $=1.73,95 \% \mathrm{CI}, 1.03-2.90, P=0.039$ ) adjustment. Similarly, in the log-additive model, rs 10007052 also showed significant association with COPD risk before (OR $=1.43,95 \% \mathrm{CI}, 1.05-1.95, P=0.022)$ and after $(\mathrm{OR}=1.68$, 95\% CI, 1.06-2.65, $P=0.026$ ) adjustment (Table 3). However, in the over-dominant model, the C/A genotype of rs 10007052 conferred an increased risk before $(\mathrm{OR}=1.49,95 \% \mathrm{CI}, 1.03-$ $2.17, P=0.037)$ but not after $(\mathrm{OR}=1.55,95 \% \mathrm{CI}, 0.91-2.64$, $P=0.100$ ) adjustment for age, sex, and smoking.

In contrast, the genotype " $\mathrm{C} / \mathrm{T}-\mathrm{C} / \mathrm{C}$ " of $\mathrm{rs} 3733829$ in the EGLN2 gene showed a decreased risk in the dominant model before $(\mathrm{OR}=0.69,95 \% \mathrm{CI}, 0.49-0.98, P=0.041)$ and after $(\mathrm{OR}=0.55,95 \% \mathrm{CI}, 0.33-0.90, P=0.018)$ adjustment for age, sex, and smoking (Table 4). Moreover, in the log-additive

Table I Characteristics of COPD patients and control participants

\begin{tabular}{|c|c|c|c|c|c|}
\hline & \multicolumn{2}{|c|}{ Cases $(n=200)$} & \multicolumn{2}{|c|}{ Controls $(n=40 I)$} & \multirow[t]{2}{*}{$P$-value from $\chi^{2}$ test } \\
\hline & $\mathbf{N}$ & $\%$ & $\mathbf{N}$ & $\%$ & \\
\hline \multicolumn{6}{|l|}{ Sex } \\
\hline Female & 58 & 29.0 & 115 & 28.7 & 0.935 \\
\hline Male & 142 & 71.0 & 286 & 71.3 & \\
\hline \multicolumn{6}{|l|}{ Age (years) } \\
\hline Mean & 71.70 & & 48.58 & & $<0.001$ \\
\hline \multicolumn{6}{|l|}{ Nationality } \\
\hline Han Chinese & 166 & 83.0 & 331 & 82.5 & 0.889 \\
\hline Li Chinese & 34 & 17.0 & 70 & 17.5 & \\
\hline \multicolumn{6}{|l|}{ Smoking status } \\
\hline Nonsmoker & 103 & 51.5 & 210 & 52.4 & 0.889 \\
\hline Smoker & 97 & 48.5 & 191 & 47.6 & \\
\hline \multicolumn{6}{|l|}{ Number of smokers } \\
\hline I-10 cigarettes a day & 14 & 7.0 & 39 & 9.7 & No data \\
\hline $20+$ cigarettes a day & 26 & 13.0 & 20 & 5.0 & \\
\hline $30+$ cigarettes a day & 53 & 26.5 & 78 & 19.5 & \\
\hline \multicolumn{6}{|l|}{ Clinical stages } \\
\hline Stage I & 80 & 40.0 & & & \\
\hline Stage II & 84 & 42.0 & & & \\
\hline Stage III & 26 & 13.0 & & & \\
\hline Stage IV & 10 & 5.0 & & & \\
\hline
\end{tabular}

Abbreviation: COPD, chronic obstructive pulmonary disease. 
Table 2 Basic information on candidate tSNPs and their association with COPD risk in this study

\begin{tabular}{|c|c|c|c|c|c|c|c|c|c|}
\hline SNP ID & Gene name & Chromosome & Base change & MAF (case) & MAF (control) & P-HWE & OR (95\% Cl) & $P^{a}$ & $P^{b}$ \\
\hline rsII24480 & WNT7A & $3 p 25.1$ & $\mathrm{C} / \mathrm{T}$ & 0.228 & 0.239 & 0.782 & $0.94(0.7 \mathrm{I}-\mathrm{I} .25)$ & 0.667 & 0.665 \\
\hline rs767II67 & FAMI $3 A$ & $4 q 22.1$ & $\mathrm{~T} / \mathrm{C}$ & 0.475 & $0.48 I$ & 0.318 & $0.98(0.77-1.24)$ & 0.837 & 0.840 \\
\hline rs 10007052 & RNFI50 & $4 q 31.21$ & $\mathrm{C} / \mathrm{A}$ & 0.235 & 0.176 & 0.599 & $1.43(1.06-1.95)$ & $0.020^{*}$ & $0.02 I^{*}$ \\
\hline rs|82859| & HHIP & $4 q 31.21$ & $\mathrm{G} / \mathrm{A}$ & 0.286 & 0.298 & 0.146 & $0.95(0.72-1.23)$ & $0.68 I$ & 0.691 \\
\hline rs|3|I8928 & HHIP & $4 q 31.21$ & $\mathrm{G} / \mathrm{A}$ & $0.28 I$ & 0.288 & 0.222 & $0.97(0.74-1.27)$ & 0.821 & 0.825 \\
\hline$r s|3| 4|64|$ & HHIP & $4 q 31.21$ & $\mathrm{C} / \mathrm{T}$ & 0.290 & 0.287 & 0.221 & I.0I (0.78-I.32) & 0.913 & 0.915 \\
\hline$r s|3| 8|56|$ & TMEM I 73 & $5 q 31.2$ & $A / G$ & 0.327 & 0.383 & 0.833 & $0.78(0.6 \mathrm{I}-\mathrm{I} .0 \mathrm{I})$ & 0.057 & 0.062 \\
\hline rs385I050 & PLAC9 & $10 q 22.3$ & $\mathrm{C} / \mathrm{T}$ & 0.315 & 0.291 & 0.276 & I. $12(0.87-1.46)$ & 0.382 & 0.373 \\
\hline rs 954820 & JAKMIP3 & $10 q 26.3$ & $\mathrm{G} / \mathrm{A}$ & 0.255 & 0.248 & 1.000 & I.04 (0.79-I.37) & 0.796 & 0.792 \\
\hline rs7937 & EGLN2 & $19 q 13.2$ & $\mathrm{C} / \mathrm{T}$ & 0.413 & 0.364 & 0.829 & I.23 (0.96-I.57) & 0.101 & 0.103 \\
\hline rs3733829 & EGLN2 & $19 q 13.2$ & $\mathrm{C} / \mathrm{T}$ & 0.354 & 0.407 & 0.680 & $0.80(0.62-1.02)$ & 0.077 & 0.078 \\
\hline rs8102683 & CYP2A6 & $19 q 13.2$ & $\mathrm{~T} / \mathrm{C}$ & 0.237 & 0.232 & 0.0000478 & I.03 (0.77-I.37) & 0.836 & 0.849 \\
\hline rs7260329 & CYP2B6 & $19 q 13.2$ & $\mathrm{G} / \mathrm{A}$ & 0.305 & 0.287 & $4.397 \times 10^{-96}$ & I.09 (0.84-I.42) & 0.513 & 0.642 \\
\hline rs2823743 & C2 I orf34 & $2 \mid q 21.1$ & $\mathrm{C} / \mathrm{T}$ & 0.510 & 0.476 & 0.764 & I. $14(0.90-1.45)$ & $0.27 \mathrm{I}$ & 0.266 \\
\hline
\end{tabular}

Notes: $* P<0.05$ indicates statistical significance. $P$ a: $P$-values were calculated from chi-square tests or Fisher's exact tests; $P$ b: $P$-values were calculated from CochranArmitage trend test.

Abbreviations: $95 \% \mathrm{Cl}, 95 \%$ confidence interval; COPD, chronic obstructive pulmonary disease; HWE, Hardy-Weinberg equilibrium; MAF, minor allele frequency; OR, odds ratio; SNP, single-nucleotide polymorphisms; tSNPs, tag SNPs.

model, rs3733829 showed a significant association after further adjustment ( $\mathrm{OR}=0.68,95 \% \mathrm{CI}, 0.48-0.98, P=0.03$ [Table 4]).

LD and haplotype analyses of the SNPs in the case and control samples were further studied. We ignored pairwise distance among SNPs $>500 \mathrm{~kb}$ in the LD analysis. One block each was detected for the studied EGLN2 SNPs and HHIP SNPs by haplotype analyses. The LD for each pair of SNPs is measured by the $\mathrm{D}^{\prime}$ value, which is marked in the square. Variants with the red square indicate that the two related sites are in complete $\operatorname{LD}\left(\mathrm{D}^{\prime}=1\right)$. The two related sites, rs 1828591 and rs13118928, were in complete LD $\left(\mathrm{D}^{\prime}=1\right)$, while rs1828591 and rs13141641, as well as rs13141641 and rs13118928, were not in complete $\left(D^{\prime}=0.95\right.$ and 0.96 , respectively). The results of the association between the EGLN2 haplotype and the risk of COPD are listed in Table 5. We found that the CT haplotype was more frequent among patients with COPD and may function as a potential risk factor of COPD after adjustment (adjusted OR $=1.55,95 \%$ CI, 1.05-2.31, $P=0.029$ ). Strong levels of LD between the two SNPs rs1828591 and rs13118928 were observed (Figure 1).

\section{Discussion}

Although a number of COPD risk variants have now been identified, almost all have been through analyses based on European Caucasian populations. Because there are significant differences in the prevalence of COPD and the frequencies of genetic variations among different ethnic populations, it is greatly important to explore the effects of these variations

Table 3 Association between rs 10007052 genotypes and COPD risk under different genotypic models

\begin{tabular}{|c|c|c|c|c|c|c|c|}
\hline \multirow[t]{2}{*}{ Model } & \multirow[t]{2}{*}{ Genotype } & \multirow[t]{2}{*}{ Control } & \multirow[t]{2}{*}{ Case } & \multicolumn{2}{|c|}{ Without adjustment } & \multicolumn{2}{|c|}{ With adjustment } \\
\hline & & & & $P^{a}$ & OR $(95 \% \mathrm{Cl})$ & $P^{b}$ & OR $(95 \% \mathrm{Cl})$ \\
\hline \multirow[t]{3}{*}{ Codominant } & $\mathrm{A} / \mathrm{A}$ & $257(68.2 \%)$ & $106(57.9 \%)$ & 0.060 & 1.00 & 0.082 & 1.00 \\
\hline & $\mathrm{C} / \mathrm{A}$ & $107(28.4 \%)$ & $68(37.2 \%)$ & & $1.54(1.05-2.25)$ & & $1.63(0.95-2.79)$ \\
\hline & $\mathrm{C} / \mathrm{C}$ & $13(3.5 \%)$ & 9 (4.9\%) & & $1.68(0.70-4.04)$ & & $3.16(0.73-13.66)$ \\
\hline \multirow[t]{2}{*}{ Dominant } & $\mathrm{A} / \mathrm{A}$ & 257 (68.2\%) & $106(57.9 \%)$ & $0.018^{*}$ & 1.00 & $0.039 *$ & 1.00 \\
\hline & $\mathrm{C} / \mathrm{A}-\mathrm{C} / \mathrm{C}$ & $120(31.8 \%)$ & 77 (42.1\%) & & $1.56(1.08-2.24)$ & & $1.73(1.03-2.90)$ \\
\hline \multirow[t]{2}{*}{ Recessive } & $\mathrm{A} / \mathrm{A}-\mathrm{C} / \mathrm{A}$ & $364(96.5 \%)$ & 174 (95.1\%) & 0.410 & 1.00 & 0.180 & 1.00 \\
\hline & $\mathrm{C} / \mathrm{C}$ & $13(3.5 \%)$ & $9(4.9 \%)$ & & $\mathrm{I} .45(0.6 \mathrm{I}-3.45)$ & & $2.71(0.64-11.53)$ \\
\hline \multirow[t]{2}{*}{ Over-dominant } & $\mathrm{A} / \mathrm{A}-\mathrm{C} / \mathrm{C}$ & $270(71.6 \%)$ & 115 (62.8\%) & $0.037^{*}$ & 1.00 & 0.100 & 1.00 \\
\hline & $\mathrm{C} / \mathrm{A}$ & 107 (28.4\%) & $68(37.2 \%)$ & & $1.49(1.03-2.17)$ & & $1.55(0.91-2.64)$ \\
\hline Log-additive & - & - & - & $0.022^{*}$ & $1.43(1.05-1.95)$ & $0.026 *$ & $1.68(1.06-2.65)$ \\
\hline
\end{tabular}

Notes: $* P<0.05$ indicates statistical significance. $P$ a: $P$-values were calculated from two-sided chi-square tests or Fisher's exact tests for either genotype distribution. $P$ : $P$-values were calculated by unconditional logistic regression adjusted for age, sex, and smoking.

Abbreviations: $95 \% \mathrm{Cl}, 95 \%$ confidence interval; COPD, chronic obstructive pulmonary disease; OR, odds ratio. 
Table 4 Association between rs3733829 genotypes and COPD risk under different genotypic models

\begin{tabular}{|c|c|c|c|c|c|c|c|}
\hline \multirow[t]{2}{*}{ Model } & \multirow[t]{2}{*}{ Genotype } & \multirow[t]{2}{*}{ Control } & \multirow[t]{2}{*}{ Case } & \multicolumn{2}{|c|}{ Without adjustment } & \multicolumn{2}{|c|}{ With adjustment } \\
\hline & & & & $P^{a}$ & OR $(95 \% \mathrm{Cl})$ & $P^{b}$ & OR (95\% CI) \\
\hline \multirow[t]{3}{*}{ Codominant } & $T / T$ & $138(34.6 \%)$ & $86(43.2 \%)$ & 0.120 & 1.00 & 0.059 & 1.00 \\
\hline & $\mathrm{C} / \mathrm{T}$ & 197 (49.4\%) & $85(42.7 \%)$ & & $0.69(0.48-1.00)$ & & $0.54(0.32-0.93)$ \\
\hline & $\mathrm{C} / \mathrm{C}$ & $64(16 \%)$ & $28(14.1 \%)$ & & $0.70(0.42-1.18)$ & & $0.55(0.26-1.16)$ \\
\hline \multirow[t]{2}{*}{ Dominant } & $\mathrm{T} / \mathrm{T}$ & $138(34.6 \%)$ & $86(43.2 \%)$ & $0.04 I^{*}$ & 1.00 & $0.018^{*}$ & 1.00 \\
\hline & $\mathrm{C} / \mathrm{T}-\mathrm{C} / \mathrm{C}$ & $26 \mid(65.4 \%)$ & II $3(56.8 \%)$ & & $0.69(0.49-0.98)$ & & $0.55(0.33-0.90)$ \\
\hline \multirow[t]{2}{*}{ Recessive } & $\mathrm{T} / \mathrm{T}-\mathrm{C} / \mathrm{T}$ & 335 (84\%) & $17 \mid(85.9 \%)$ & 0.530 & 1.00 & 0.430 & 1.00 \\
\hline & $\mathrm{C} / \mathrm{C}$ & 64 (16\%) & $28(14.1 \%)$ & & $0.86(0.53-1.39)$ & & $0.76(0.38-1.52)$ \\
\hline \multirow[t]{2}{*}{ Over-dominant } & $\mathrm{T} / \mathrm{T}-\mathrm{C} / \mathrm{C}$ & $202(50.6 \%)$ & 114 (57.3\%) & 0.120 & 1.00 & 0.077 & 1.00 \\
\hline & $\mathrm{C} / \mathrm{T}$ & 197 (49.4\%) & $85(42.7 \%)$ & & $0.76(0.54-1.08)$ & & $0.64(0.39-1.05)$ \\
\hline Log-additive & - & - & - & 0.077 & $0.80(0.62-1.03)$ & $0.037^{*}$ & $0.68(0.48-0.98)$ \\
\hline
\end{tabular}

Notes: $* P<0.05$ indicates statistical significance. $P$ a: $P$-values were calculated from two-sided chi-square tests or Fisher's exact tests for either genotype distribution. $P \mathrm{~b}$ : $P$-values were calculated by unconditional logistic regression adjusted for age, sex, and smoking.

Abbreviations: $95 \% \mathrm{Cl}, 95 \%$ confidence interval; COPD, chronic obstructive pulmonary disease; OR, odds ratio.

in other populations. We therefore investigated whether the SNP at each locus was associated with COPD in Hainan Chinese population.

In this case-control study, we genotyped 14 tSNPs in the Han and Li Chinese population, and identified one risk SNP in the allelic model and two risk SNPs in the genetic model analysis. Our results suggest that polymorphisms of the corresponding genes may play an important role in the risk of COPD among the Chinese population in Hainan province.

$R N F 150$ (ring finger protein 150) encodes a RING finger (RNF) protein. An important paralogue of this gene is ZNRF3. A large number of RNF proteins are present in eukaryotic cells, and the majority of them are believed to function as E3 ubiquitin ligases. ${ }^{25}$ The human genome encodes approximately 300 RNF proteins, many of which are soluble proteins that play a role in a variety of cellular functions, including oncogenesis, development, signal transduction, cell cycle and apoptosis, protein quality control, protein trafficking, cell proliferation and differentiation, apoptosis, immune regulation, signaling, and mitochondrial dynamics. ${ }^{26,27}$ The rs10007052 SNP in RNF150 did not reach genome-wide statistical significance regarding its relationship to COPD in Europeans in a previously reported GWA study. ${ }^{13}$ To our knowledge, the present study is the first report that polymorphisms of RNF150 affect the pathogenesis of COPD in a Chinese Han and Li population, and these findings provide novel insight into the pathogenesis of COPD. However, the underlying mechanisms of the functional changes induced by mutated RNF150 are not fully understood and need to be further elucidated; this represents a future direction of study on RNF150. Although our present study indicated the novel association between $R N F 150$ polymorphisms and risk of COPD development, there are some intrinsic limitations. First, the sample size in our study was relatively small. Second, the race of all of the studied participants was Han and Li Chinese. Whether the conclusions of the present study also apply to other races needs to be clarified.

EGLN2 (Egl nine homolog 2) is one of three similar genes that act in the hypoxia-response pathway and is widely expressed in multiple tissues including brain, lung, and muscle. EGLN2 regulates the activity of NF-kB, a key transcriptional factor involved in activation of inflammatory and immune genes, including those implicated in COPD pathogenesis. ${ }^{28,29}$ Relevant to the disordered epithelium observed in COPD, EGLN2 increases cell proliferation through the regulation of cyclin D. ${ }^{30}$ It has been reported that increased $E G L N 2$ expression is associated with impaired epithelial junctional barrier

Table 5 EGLN2 haplotype frequencies and their associations with COPD risk

\begin{tabular}{|c|c|c|c|c|c|c|c|}
\hline Block & Haplotype & Frequency & OR (95\% CI) & $P^{a}$ & Frequency & OR (95\% CI) & $P^{b}$ \\
\hline I & $\mathrm{TC}$ & 0.3876 & 1.00 & - & 0.3883 & 1.00 & - \\
\hline 2 & $\mathrm{CT}$ & 0.3772 & $1.31(1.00-1.73)$ & 0.055 & 0.3793 & I.55 (I.05-2.3I) & $0.029 *$ \\
\hline 3 & TT & 0.2331 & $1.15(0.84-1.57)$ & 0.39 & 0.23 & $1.30(0.83-2.05)$ & 0.26 \\
\hline
\end{tabular}

Notes: $P$ a: $P$-values were calculated from two-sided chi-square tests or Fisher's exact tests for either genotype distribution. $P$ : $P$-values were calculated by unconditional logistic regression adjusted for age, sex, and smoking. $* P<0.05$ indicates statistical significance.

Abbreviations: $95 \% \mathrm{Cl}, 95 \%$ confidence interval; COPD, chronic obstructive pulmonary disease; OR, odds ratio. 


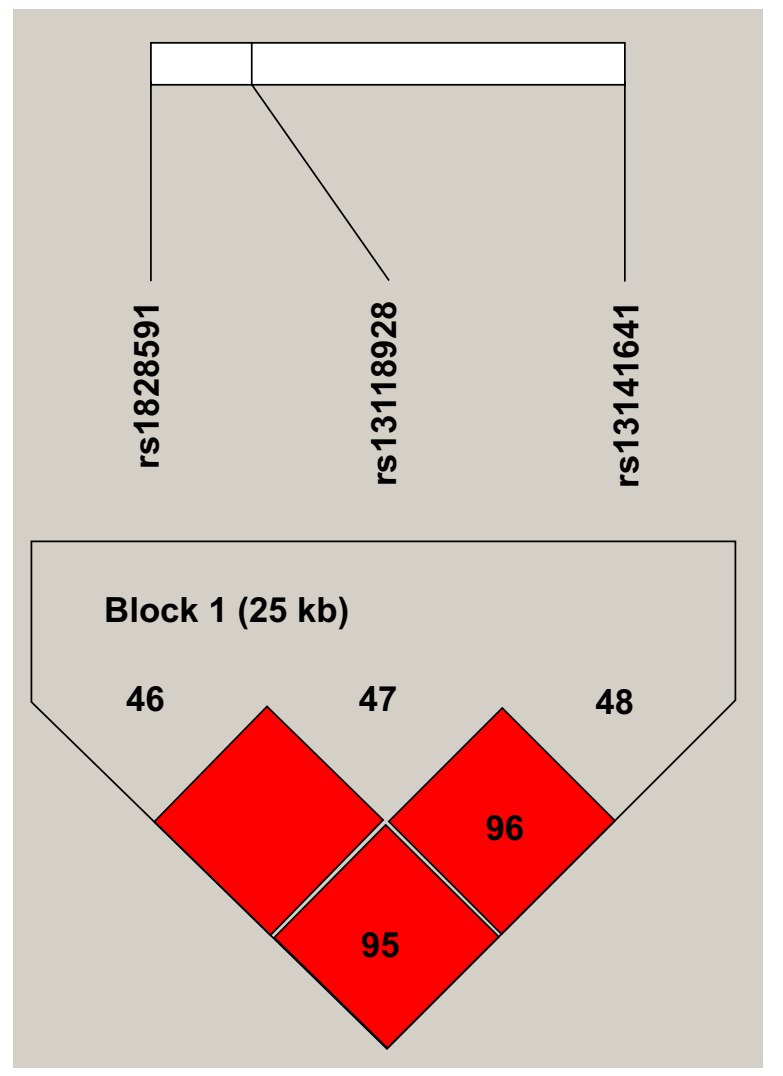

Figure I Haplotype block map for the HHIP tSNPs genotyped in this study. Notes: Block I includes rs|82859I, rs/314164I, and rs/31/8928; the linkage disequilibrium between two SNPs is indicated by standardized D' (red boxes). Abbreviations: SNP, single-nucleotide polymorphism; tSNPs, tag SNPs.

function, which leads to increased epithelial permeability. ${ }^{31}$ A recent GWA study found an association of EGLN2 with COPD risk..$^{13}$ The polymorphism, rs 3733829 , lies in the first intron of the EGLN2 gene, which is located on chromosome $19 \mathrm{q} 13,40 \mathrm{~kb}$ on the $3^{\prime}$ end of CYP2A6. Because of the proximity of EGLN2 to CYP2A6, rs3733829 was assumed to be a proxy for functional genetic variation in $C Y P 2 A 6 .{ }^{15} \mathrm{CYP} 2 \mathrm{~A} 6$ is an established candidate gene for smoking addiction because it encodes an enzyme involved in the metabolic inactivation of nicotine to cotinine. ${ }^{32}$ An association between rs3733829 and EGLN2 mRNA levels has been demonstrated in monocytes and lymphocytes, ${ }^{32,34}$ and another study reported a potential role in smoking behavior. ${ }^{15} \mathrm{We}$ found that rs3733829 had a significant effect on COPD risk in the Hainan population; however, because our sample size was relatively small, we did not conduct population stratification of smokers, therefore, we have not confirmed that this locus is significant in smokers. We will increase the sample size in subsequent experiments.

Despite the current study possessing enough power, some limitations should be considered. Firstly, because our sample size was relatively small, we did not conduct population stratification of smokers, therefore, we have not confirmed that this locus is significant in smokers. We will increase the sample size in subsequent experiments. Secondly, the heterogeneity in smoking behaviors and comorbidities was not evaluated in this study, and evaluation of heterogeneity in smoking behaviors has contributed to the progress in elucidating the pathogenesis of COPD in other studies.

Two previous GWA studies showed that two SNPs near the HHIP gene (rs13118928 and rs1828591) are associated with COPD and lung function in non-Asian populations. ${ }^{910}$ Although our results did not indicate that either rs13118928 or rs1828591 were associated with COPD or lung function in the Chinese Han population, strong levels of LD between rs1828591 and rs13118928 were observed, which was reflected in the very similar ORs obtained in our analysis of the distribution of these two SNPs in COPD patients and controls.

\section{Conclusion}

In summary, our present study provides the first demonstration that the rs10007052 SNP of the RNF150 gene and rs3733829 of the EGLN2 gene are significantly associated with the risk of COPD in Chinese populations of Hainan province. In addition to the potential role of $E G L N 2$ genetic polymorphisms in COPD development, our findings suggest that polymorphisms of $R N F 150$ may be a novel underlying mechanism of COPD pathogenesis.

\section{Acknowledgments}

This work was supported by the National Natural Science Foundation of China (No 81160008). We thank all of the participants for their involvement in this study.

\section{Disclosure}

The authors report that they have no conflicts of interests in this work.

\section{References}

1. Vestbo J, Hurd SS, Agusti AG, et al. Global strategy for the diagnosis, management, and prevention of chronic obstructive pulmonary disease: GOLD executive summary. Am J Respir Crit Care Med. 2013; 187:347-365.

2. Murray CJ, Lopez AD. Alternative projections of mortality and disability by cause 1990-2020: Global Burden of Disease Study. Lancet. 1997; 349:1498-1504.

3. Mannino DM. COPD: epidemiology, prevalence, morbidity and mortality, and disease heterogeneity. Chest. 2002;121:121S-126S.

4. Burrows B, Knudson RJ, Cline MG, Lebowitz MD. A reexamination of risk factors for ventilatory impairment. Am Rev Respir Dis. 1988;138:829-836.

5. Mannino DM, Buist AS, Petty TL, Enright PL, Redd SC. Lung function and mortality in the United States: data from the First National Health and Nutrition Examination Survey follow up study. Thorax. 2003;58:388-393. 
6. Aaron SD, Fergusson D, Dent R, Chen Y, Vandemheen KL, Dales RE. Effect of weight reduction on respiratory function and airway reactivity in obese women. Chest. 2004;125:2046-2052.

7. Berndt A, Leme AS, Shapiro SD. Emerging genetics of COPD. EMBO Mol Med. 2012;4:1144-1155.

8. Hoidal JR. Genetics of COPD: present and future. Eur Respir J. 2001;18:741-743.

9. Wilk JB, Chen TH, Gottlieb DJ, et al. A genome-wide association study of pulmonary function measures in the Framingham Heart Study. PLoS Genet. 2009;5:e1000429.

10. Pillai SG, Ge D, Zhu G, et al. A genome-wide association study in chronic obstructive pulmonary disease (COPD): identification of two major susceptibility loci. PLoS Genet. 2009;5:e1000421.

11. Hancock DB, Eijgelsheim M, Wilk JB, et al. Meta-analyses of genome-wide association studies identify multiple loci associated with pulmonary function. Nat Genet. 2010;42:45-52.

12. Rabe KF, Hurd S, Anzueto A, et al. Global strategy for the diagnosis, management, and prevention of chronic obstructive pulmonary disease: GOLD executive summary. Am J Respir Crit Care Med. 2007;176:532-555.

13. Kim DK, Cho MH, Hersh CP, et al. Genome-wide association analysis of blood biomarkers in chronic obstructive pulmonary disease. Am J Respir Crit Care Med. 2012;186:1238-1247.

14. Cho MH, Boutaoui N, Klanderman BJ, et al. Variants in FAM13A are associated with chronic obstructive pulmonary disease. Nat Genet. 2010;42:200-202.

15. Tobacco and Genetics Consortium. Genome-wide meta-analyses identify multiple loci associated with smoking behavior. Nat Genet. 2010;42:441-447.

16. Kumasaka N, Aoki M, Okada Y, et al. Haplotypes with copy number and single nucleotide polymorphisms in CYP2A6 locus are associated with smoking quantity in a Japanese population. PloS One. 2012;7:e44507.

17. Thorgeirsson TE, Gudbjartsson DF, Surakka I, et al. Sequence variants at CHRNB3-CHRNA6 and CYP2A6 affect smoking behavior. Nat Genet. 2010;42:448-453.

18. Gabriel S, Ziaugra L, Tabbaa D. SNP genotyping using the Sequenom MassARRAY iPLEX platform. Curr Protoc Hum Genet 2009; Chapter 2:Unit 2. 12

19. Thomas RK, Baker AC, Debiasi RM, et al. High-throughput oncogene mutation profiling in human cancer. Nat Genet. 2007;39:347-351.

20. Bland JM, Altman DG. Statistics notes. The odds ratio. BMJ. 2000; 320:1468.
21. Solé X, Guinó E, Valls J, Iniesta R, Moreno V. SNPStats: a web tool for the analysis of association studies. Bioinformatics. 2006;22(15):1928-1929.

22. Shi YY, He L. SHEsis, a powerful software platform for analyses of linkage disequilibrium, haplotype construction, and genetic association at polymorphism loci. Cell Res. 2005;15(2):97-98.

23. Barrett JC, Fry B, Maller J, Daly MJ. Haploview: analysis and visualization of LD and haplotype maps. Bioinformatics. 2005;21:263-265.

24. Teramoto S, Ishii T, Yamamoto H, Yamaguchi Y, Matsuse T. Xenobiotic enzymes and genetics of COPD. Chest. 2005;127:408-409.

25. Campbell SJ, Edwards RA, Leung CC, et al. Molecular insights into the function of RING finger (RNF)-containing proteins hRNF8 and hRNF168 in Ubc13/Mms2-dependent ubiquitylation. J Biol Chem. 2012;287:23900-23910.

26. Darom A, Bening-Abu-Shach U, Broday L. RNF-121 is an endoplasmic reticulum-membrane E3 ubiquitin ligase involved in the regulation of beta-integrin. Mol Biol Cell. 2010;21:1788-1798.

27. Borden KL. RING fingers and B-boxes: zinc-binding protein-protein interaction domains. Biochem Cell Biol. 1998;76:351-358.

28. Cummins EP, Berra E, Comerford KM, et al. Prolyl hydroxylase-1 negatively regulates IkappaB kinase-beta, giving insight into hypoxia-induced NFkappaB activity. Proc Natl Acad Sci U S A 2006;103:18154-18159.

29. Bloom AJ, Baker TB, Chen LS, et al. Variants in two adjacent genes, EGLN2 and CYP2A6, influence smoking behavior related to disease risk via different mechanisms. Hum Mol Genet. 2014;23:555-561.

30. Zhang Q, Gu J, Li L, et al. Control of cyclin D1 and breast tumorigenesis by the Eg1N2 prolyl hydroxylase. Cancer Cell. 2009;16: 413-424.

31. Tambuwala MM, Cummins EP, Lenihan CR, et al. Loss of prolyl hydroxylase-1 protects against colitis through reduced epithelial cell apoptosis and increased barrier function. Gastroenterology. 2010;139:2093-2101.

32. Chen LS, Baker TB, Grucza R, et al. Dissection of the phenotypic and genotypic associations with nicotinic dependence. Nicotine Tob Res. 2012;14:425-433.

33. Zeller T, Wild P, Szymczak S, et al. Genetics and beyond - the transcriptome of human monocytes and disease susceptibility. PloS One. 2010;5:e10693.

34. Goring HH, Curran JE, Johnson MP, et al. Discovery of expression QTLs using large-scale transcriptional profiling in human lymphocytes. Nat Genet. 2007;39:1208-1216.
International Journal of COPD

\section{Publish your work in this journal}

The International Journal of COPD is an international, peer-reviewed journal of therapeutics and pharmacology focusing on concise rapid reporting of clinical studies and reviews in COPD. Special focus is given to the pathophysiological processes underlying the disease, intervention programs, patient focused education, and self management protocols.

\section{Dovepress}

This journal is indexed on PubMed Central, MedLine and CAS. The manuscript management system is completely online and includes a very quick and fair peer-review system, which is all easy to use. Visit http://www.dovepress.com/testimonials.php to read real quotes from published authors. 